\title{
Overexpression of an alternative allele of carboxyl/choline esterase 4 (CCE04) of Tetranychus urticae is associated with high levels of resistance to the keto-enol acaricide spirodiclofen
}

Running title: Overexpression of CCE04 is associated with spirodiclofen resistance in Tetranychus urticae

Peng Wei ${ }^{\mathrm{a}, \mathrm{b}, *}$, Peter Demaeght ${ }^{\mathrm{b}, \mathrm{c}^{*}}$, Kristof De Schutter ${ }^{\mathrm{b}}$, Linda Grigoraki ${ }^{\mathrm{d}, \mathrm{e}}$, Vassiliki Labropoulou $^{\mathrm{f}}$, Maria Riga ${ }^{\mathrm{d}}$, John Vontas ${ }^{\mathrm{d}, \mathrm{e}}$, Ralf Nauen ${ }^{\mathrm{g}}$, Wannes Dermauw ${ }^{\mathrm{b},{ }^{* *}}$, Thomas Van Leeuwen ${ }^{\text {b,** }}$

${ }^{\mathrm{a}}$ College of Plant Protection, Southwest University, $2^{\text {nd }}$ Tiansheng road, Beibei district, Chongqing, P.R. China

${ }^{b}$ Department of Plants and Crops, Faculty of Bioscience Engineering, Ghent University, Coupure links 653, 9000, Ghent, Belgium

${ }^{c}$ current address: Department of Biochemistry and Microbiology, Faculty of Sciences, Ghent University,K.L. Ledeganckstraat 35, 9000 Ghent, Belgium

${ }^{\mathrm{d}}$ Molecuar Entomology Lab, Institute of Molecular Biology and Biotechnology (IMBB), Foundation for Research and Technology (FORTH), Nikolaou Plastira Street 100, 70013, Heraklion, Crete, Greece

${ }^{e}$ Pesticide Science Laboratory, department of Crop Science, Agricultural University of Athens, Iera Odos 75, 11855, Athens, Greece

${ }^{\mathrm{f}}$ Insect Molecular Genetics and Biotechnology, Institute of Biosciences and Applications, National Centre for Scientific Research, 'Demokritos' P.O. Box 60228, Aghia Paraskevi 153 10, Athens, Greece

${ }^{\mathrm{g}}$ Bayer AG, CropScience Division, R\&D, Pest Control, Building 6260, Alfred Nobel Str. 50, D-40789 Monheim, Germany

\footnotetext{
*equally contributed

**corresponding authors: wannes.dermauw@ugent.be; thomas.vanleeuwen@ugent.be
} 


\begin{abstract}
BACKGROUND

Spirodiclofen is an acaricide that targets lipid biosynthesis by inhibiting acetylcoenzyme A carboxylase. Spirodiclofen resistance in spider mites has been previously documented and was associated with overexpression of CYP392E10, a cytochrome P450 mono-oxygenase that metabolizes spirodiclofen. However, additional mechanisms have been suggested in several studies and a carboxyl/choline esterase gene, CCE04, was shown to be overexpressed in two genetically different strains, SR-VP and SR-TK, both exhibiting high spirodiclofen resistance levels
\end{abstract}

\title{
RESULTS
}

We identified two different CCEO4 alleles in both resistant strains, CCEO4 ${ }^{S R-V P}$ and

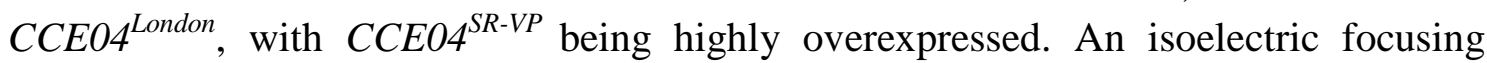
analysis confirmed the overexpression of a single esterase isozyme, while copy number and RFLP analysis revealed that $C C E O 4^{S R-V P}$ overexpression was more likely due to selection for the $C C E O 4^{S R-V P}$ allele rather than gene amplification. Both $C C E O 4$ alleles were functionally expressed using the Pichia expression system. Functional enzyme assays revealed only limited kinetic differences between CCE04 isoforms for model substrates. In addition, the inhibition/competition experiments with spirodiclofen suggested a similar interaction with both enzymes, while its active metabolite, spirodiclofen enol, did not inhibit enzyme activity.

\section{CONCLUSION}

Our study suggests that selection with spirodiclofen results in enrichment of a specific allele of CCEO4 (CCEO4 $4^{S R-V P}$ ) in two genetically independent strains, which is highly overexpressed. Based on kinetic enzyme data, however, quantitative differences rather than qualitative differences between $\mathrm{CCE} 04^{\mathrm{SR}-\mathrm{VP}}$ and $\mathrm{CCE} 04^{\mathrm{London}}$ seem more likely to be involved in resistance. Our findings are discussed in the light of a possible spirodiclofen resistance mechanism, with sequestration of spirodiclofen by CCE0 $4^{\text {SR-VP }}$ being a likely hypothesis.

Key words: sequestration, spirodiclofen, cyclic keto-enol, resistance, allele-specific expression 


\section{Introduction}

Acaricides have been used intensively in the past 70 years to control spider mite populations, which resulted in wide-spread resistance to compounds with different mode of actions. ${ }^{1,2}$ Although biological control of spider mites has been successfully implied in some cropping systems (such as glass-house vegetables), many crops are still heavily dependent on chemical control. ${ }^{3}$ Therefore, the addition of compounds with a new mode of action showing no cross-resistance to currently employed chemistry, is of crucial importance. The spirocyclic tetronic acid derivatives (keto-enols), such as spirodiclofen and spiromesifen, are amongst the most recently introduced compounds for mite control with an activity spectrum including genera such as Tetranychus, Panonychus, Brevipalpus and Aculus. ${ }^{4}$ These acaricides are inhibitors of acetylcoenzyme A carboxylase (ACCase, EC 6.4.1.2), the rate limiting enzyme in lipid biosynthesis. ACCase catalyzes the carboxylation of acetyl-CoA to malonyl-CoA. Catalysis is biotin-dependent and proceeds through two separate half-reactions: first biotin is carboxylated followed by the transfer of the carboxyl group from carboxybiotin to the acyl-CoA acceptor. Tetronic acids specifically interfere with the carboxyltransferase partial reaction where they act as competitive inhibitors of acetylcoenzyme $\mathrm{A}$ and uncompetitive inhibitors with regard to the biotin carboxylase substrate ATP. ${ }^{5}$

Resistance screening indicated moderate to high spirodiclofen resistance levels in $T$. urticae field populations ${ }^{6,7}$. In addition, high levels of spirodiclofen resistance $\left(\mathrm{LC}_{50}>\right.$ $1000 \mathrm{mg}$ a.i./L) have also been reported for laboratory selected spider mite strains: the genetically distinct $T$. urticae strains SR-VP and SR-TK and the Panonychus ulmi strain

PSR-TK. ${ }^{8-10}$ A genome wide gene expression analysis of SR-VP and SR-TK revealed that multiple detoxification enzymes might contribute to resistance, with several 
cytochrome P450 mono-oxygenase (P450s) genes, including cyp392e7 and cyp392e10, being overexpressed in both resistant strains. In contrast to CYP392E7, we were able to functionally express CYP392E10 and showed that CYP392E10 could metabolize spirodiclofen, but not its corresponding enol. ${ }^{11}$

In this study, we focus on the role of additional resistance mechanisms, more specifically the involvement of carboxyl/choline esterases (CCEs), for the following reasons: (1) classical genetics revealed that spirodiclofen resistance in $T$. urticae was not controlled by a single gene ${ }^{12}$ and suggested that additional mechanisms next to P450 metabolism are highly likely, which was confirmed by a recent QTL study ${ }^{13}$; (2) synergism experiments have previously pointed out the involvement of both P450s and CCEs in spirodiclofen resistance in spider mites, which was confirmed by enzymatic assays $^{9}{ }^{14-16}$; (3) microarray analysis revealed that a single CCE gene (CCEO4) was highly overexpressed in two genetically distinct $T$. urticae strains (SR-VP and SR-TK) ${ }^{11}$, while transcriptome analysis of a spirodiclofen resistant $P$. ulmi strain revealed that the overexpression of a CCE was strongly associated with spirodiclofen resistance. ${ }^{10}$

Together with P450s and glutathione-S-transferases (GSTs), CCEs can confer metabolic resistance to some of the major classes of insecticides. ${ }^{1,17,18}$ CCE-mediated resistance has been reported for more than 30 veterinary, medicinal and agricultural pests and CCEs are frequently implicated in resistance to organophosphates (OPs), carbamates and pyrethroids. ${ }^{19-22}$ Esterases are a large, heterogenous group of enzymes that hydrolyze endogenous and exogenous ester compounds. ${ }^{18,22}$ Traditionally, they have been classified since the early work of Aldridge and colleagues ${ }^{23,24}$ in 3 groups (Aesterase, B-esterase, C-esterases) based on their interaction with organophosphate (OP) compounds and other inhibitors. Although convenient, this classification is not always straightforward, as the inhibition pattern of A and B type esterases does not always 
corresponds to substrate preferences, and single point mutations can convert a Besterase into an A-esterase. ${ }^{22}$ It is therefore since long widely recognized that esterase nomenclature should be revised and attempts to classify esterases based on a thorough phylogenetic analysis are ongoing. ${ }^{21,25,26}$

CCEs can play a role in resistance through two main mechanisms: sequestration and metabolism. ${ }^{21,22,27}$ In the case of sequestration, the CCE will bind with the insecticide and act as a 'sink', thereby reducing the availability at the insecticide target site. ${ }^{21,22}$ CCEs involved in such type of resistance have a poor metabolic activity against the insecticide, but they are produced in such large quantities that they are able to prevent the insecticide from binding to its target. ${ }^{22}$ In the best studied cases (aphids and mosquitoes), gene amplification or duplication has been reported as the main mechanism behind overexpression. ${ }^{17,} 20,28$ CCEs can also directly metabolize insecticides, as is relatively well documented for some OPs and pyrethroids. ${ }^{29,}{ }^{30}$ Point mutations have been described that alter the catalytic properties of the enzymes, enhancing the capability of insecticide metabolism. ${ }^{20,31,32}$ With the exception of AChEs, CCEs have only been indirectly implicated in resistance of $T$. urticae to various acaricides e.g. bifenthrin and chlorfenapyr, and detailed molecular evidence has been lacking. ${ }^{33-36}$

We report here on the discovery and association of a specific allele of CCEO4 with spirodiclofen resistance in $T$. urticae, by analyzing gene expression, determining CCEO4 copy number, and finally by studying recombinantly produced and purified CCE04 isoforms for their steady state enzyme kinetics and interaction with spirodiclofen. 


\section{Materials and methods}

\subsection{Acaricides}

Spirodiclofen (Envidor, $240 \mathrm{~g} / \mathrm{L}$ SC) was provided by Bayer AG (Monheim, Germany)

\subsection{Spider mite strains}

The London strain is a reference susceptible laboratory strain and was used for sequencing of the complete T. urticae genome. ${ }^{37} \mathrm{LS}-\mathrm{VL}$ originates from a rose garden near Ghent (Belgium) and is susceptible to most currently available acaricides. ${ }^{33}$ The spirodiclofen resistant strains SR-VP and SR-TK are maintained on bean plants sprayed with 5000 and $1000 \mathrm{mg} / \mathrm{L}$ spirodiclofen, respectively. SR-VP was selected out of LSVL following successive applications of spirodiclofen (as described in Van Pottelberge et al. 2009) and showed a 274 -fold spirodiclofen resistance ratio. ${ }^{9}$ SR-TK is a fieldcollected strain from Belgium which was further selected with spirodiclofen. Other strains used were previously described and include the multi-resistant strains MR-VL ${ }^{38}$ (resistant to dicofol, fenbutatin oxide and bifenthrin), MR-VP ${ }^{39}$ (a Belgian strain resistant to mitochondrial electron transport inhibitors (METI-Is)), Akita ${ }^{15}$ (a Japanese METI-I resistant strain), BR-VL ${ }^{40}$ (resistant to bifenazate and selected out of LS-VL). All strains are maintained on 3-week-old potted kidney beans plants (Phaseolus vulgaris L cv Prelude) in a climatically controlled room at $26 \pm 0.5{ }^{\circ} \mathrm{C}, 60 \% \mathrm{RH}$ and 16:8 h light:dark photoperiod.

\subsection{Microarray validation by quantitative PCR}

Gene expression microarray data (SR-VP or SR-TK against LS-VL) was validated using quantitative PCR (qPCR) as previously described. ${ }^{11}$ Primers for the genes of interest and a set of two reference genes [actin (tetur03g09480) and ribosomal protein gene rp49 (tetur18g03590)] are listed in Table S1. A gene of interest, CCE04, was 
highly overexpressed in both resistant strains and belongs to the CCE multigene family. To identify other CCE genes that might cross-hybridize with CCEO4 microarray probes, a BLASTn analysis, with default parameters, was conducted against the T. urticae annotation using CCE04 probes (CUST_124 and CUST_125 in Agilent microarray design $028213^{11}$ ) as query. Total RNA was extracted from approximately 200 deutonymphs of each strain (LS-VL, SR-VP and SR-TK), using the RNeasy Mini Kit (Qiagen), according to the manufacturer's instructions. The RNA was treated with Turbo DNase (Ambion) to remove genomic DNA contamination. The quantity and quality of the RNA samples were assessed with the NanoDrop ND-1000 spectrophotometer (Nanodrop Technologies) and agarose gel analysis. RNA samples were stored at $-80{ }^{\circ} \mathrm{C}$ before use. Two $\mu \mathrm{g}$ of total RNA was used to synthesize first strand cDNA using the Maxima First Strand cDNA kit (Fermentas Life Sciences). The cDNA samples were diluted 10-fold with ultrapure water before use. The qPCR reactions were performed on a Mx3005P qPCR system (Stratagene) using the Maxima SYBR green qPCR mastermix with ROX solution (Fermentas Life Sciences) according to the manufacturer's instructions. A 4-fold dilution series of pooled cDNA was used to evaluate the efficiency of the qPCR reaction for the gene-specific primer pair. A no template control (NTC) was also included to detect possible contamination. Experiments were performed using 3 biological and 2 technical replicates for each gene. A dissociation curve analysis was performed to check for the presence of a single amplicon. Relative expression levels were calculated according to Pfaffl. ${ }^{41}$ Significant differences in gene expression were identified by pair-wise fixed reallocation randomization. $^{41}$

\subsection{Separation of esterases using isoelectric focusing (IEF)}


Approximately 300 female adults or deutonymphs were homogenized in $400 \mu$ l sodium phosphate buffer $(0.1 \mathrm{M}, \mathrm{pH} 7.0)$ and centrifuged for 10 minutes at $21.000 \mathrm{~g}$. After collecting the supernatant, samples were diluted to obtain a concentration of $2 \mu \mathrm{g} / \mu \mathrm{L}$ protein. IEF was conducted using the XCell SureLock Mini-Cell (Invitrogen) using Novex $\mathrm{pH}$ 3-7 IEF precast protein gels $(1.0 \mathrm{~mm}$, Invitrogen). Approximately $12 \mu \mathrm{g}$ of protein was loaded into each well. Gels were run according to the manufacturer's instructions at $100 \mathrm{~V}$ for $1 \mathrm{~h}, 200 \mathrm{~V}$ for $1 \mathrm{~h}$ and $500 \mathrm{~V}$ for $30 \mathrm{~min}$ at $4{ }^{\circ} \mathrm{C}$. Esterases were visualized according to Van Leeuwen et al. 2005. ${ }^{38}$ Briefly, after electrophoresis, gels were washed in $50 \mathrm{~mL}$ deionized water, after which $50 \mathrm{ml}$ of sodium phosphate buffer $(0.1 \mathrm{M}, \mathrm{pH} 7)$ was added. Next, the gel was incubated at $30{ }^{\circ} \mathrm{C}$ in the dark, after adding $4 \mathrm{ml}$ of a $10 \mathrm{~g} / \mathrm{L}$ 1-naphthyl-acetate mixture in $100 \mathrm{ml}$ acetone-deionized water $(1: 1$ volume) with $80 \mathrm{mg}$ of Fast Blue RR salt to visualize the esterases. After a $20 \mathrm{~min}$ incubation with continuous shaking, the gels were rinsed with $10 \%$ acetic acid solution to remove excess staining and fixed in a mixture of $30 \mathrm{ml} / \mathrm{L}$ methanol, acetic acid 10 $\mathrm{ml} / \mathrm{L}$ and glycerine $10 \mathrm{ml} / \mathrm{L}$ in deionized water.

\subsection{Rapid amplification of cDNA ends (RACE) of the resistant CCE04 allele and subsequent cloning and sequencing}

Total RNA was isolated using the RNeasy Mini kit (Qiagen) according to the manufacturer's instructions. First strand cDNA was synthesized from total RNA, using the SMARTer®RACE cDNA amplification kit according to the manufacturer's instructions (ClonTech; Table S1). First, the 5'-CDS primer A (provided by the RACE kit) and total RNA were combined, mixed and incubated at $72{ }^{\circ} \mathrm{C}$ for $3 \mathrm{~min}$, followed by $2 \mathrm{~min}$ at $42{ }^{\circ} \mathrm{C}$ and centrifugation for $10 \mathrm{~s}$ at $14,000 \mathrm{~g}$. One $\mu \mathrm{l}$ of the SMARTer II A oligonucleotide is added to the sample. Next, 5x First-Strand buffer, dNTP's (10 mM), DTT (20 mM), RNAse inhibitor $(40 \mathrm{U} / \mu \mathrm{l})$ and SMARTScribe reverse transcriptase 
(100U) are added to the denatured RNA and incubated at $42^{\circ} \mathrm{C}$ for $90 \mathrm{~min}$, followed by 10 min at $70{ }^{\circ} \mathrm{C}$ to terminate the reaction. cDNA samples were diluted with TricineEDTA buffer. PCR amplification was performed on newly synthesized cDNA with the expand long range dNTPack (Roche) in a Biometra TProfessional Thermocycler (Biometra). PCR reactions were performed in $50 \mu 1$, containing 5x Expand Long Range buffer (with $12.5 \mathrm{mM} \mathrm{MgCl}$ ), $0.5 \mathrm{mM}$ dNTP mix, $0.3 \mu \mathrm{M}$ of each primer (5-CCE04 and 5n-CCE04), $1 \mu \mathrm{l}$ of template and 3.5U Expand Long Range enzyme mix. PCR reactions were performed under the following conditions: initial denaturation step of 2 min at $92{ }^{\circ} \mathrm{C} ; 10$ cycles of $10 \mathrm{~s}$ at $92{ }^{\circ} \mathrm{C}, 10 \mathrm{~s}$ at $55^{\circ} \mathrm{C}$ and $30 \mathrm{~s}$ at $68^{\circ} \mathrm{C} ; 25$ cycles of 10 $\mathrm{s}$ at $92{ }^{\circ} \mathrm{C}, 15 \mathrm{~s}$ at $55^{\circ} \mathrm{C}$ and $30 \mathrm{~s}$ (adding $20 \mathrm{~s}$ to each successive cycle) at $68{ }^{\circ} \mathrm{C}$; followed by a final elongation step of $5 \mathrm{~min}$ at $68{ }^{\circ} \mathrm{C}$. PCR products were purified using the E.Z.N.A. Cycle Pure kit (Omega Biotek) and subsequently ligated in a pJET1.2 vector using the CloneJET PCR cloning kit (Thermo Scientific) and transformed into chemically competent $E$. coli cells, according to the manufacturer's instructions. Plasmid DNA was extracted from overnight bacterial cultures using the E.Z.N.A. Plasmid Mini kit (Omega Biotek) and send for sequencing with the pJET forward and reverse primers (Table S1).

\subsection{Analysis of CCE04 and position within T. urticae CCE phylogeny}

The ScanProsite tool at the ExPASy PROSITE web server ((http://www.expasy.org/prosite/) was used to identify signature motifs in both CCE04 variants, $\mathrm{CCE} 04^{\mathrm{SR}-\mathrm{VP}}$ and $\mathrm{CCE} 04^{\mathrm{LS}-\mathrm{VL}}$, while SignalP 4.0 (with default settings for eukaryotes) was used to predict signal peptides. ${ }^{42}$ Next, we performed a maximum likelihood phylogenetic analysis to determine the phylogenetic position of CCE04 ${ }^{\text {SR-VP }}$ within T. urticae CCE phylogeny. Sixty-nine T. urticae CCEs (two out of the 71 CCEs identified CCE genes in Grbic et al. 2011 were, after publication, considered as 
pseudogenes) were aligned with those of D. melanogaster, A. mellifera ${ }^{43}$, a selection of L. polyphemus CCEs and both AChEs of Bombyx mori and Daphnia pulex, using the online version of MAFFT v7.427 $7^{44}$ and the L-INS-I option (settings used: “--reorder -maxiterate 1000 --retree 1 --localpair input"). The Cipres web portal was used to perform a phylogenetic analysis ${ }^{45}$ using RAxML v8 HPC2-XSEDE ${ }^{46}$ with the automatic protein model assignment algorithm using maximum likelihood criterion and 500 bootstrap replicates. The WAG model with empirical base frequencies was chosen as the best scoring model by RAxML. The resulting tree was visualized, midpoint rooted and optimized with MEGA6 ${ }^{47}$ and edited in Corel-DRAW Home \& Student x7.

\subsection{Stage-specific expression, induction and copy number determination}

To quantify gene expression levels in different life stages of T. urticae, samples were prepared as described in Demaeght et al. 2013. ${ }^{11}$ For the induction experiment, bean $(P$. vulgaris cv Prelude) leaf discs were sprayed with either water or spirodiclofen (5000 mg a.i./L), as previously described ${ }^{48}, 3-5$ day old adult females from SR-VP or LS-VL were placed on untreated and treated leaf disks and allowed to feed for 48 hours. The following treatments were generated: LS-VL not-induced, LS-VL induced, SR-VP notinduced and SR-VP induced. After 48 hours of exposure, mortality was less than $10 \%$ for both strains, as spirodiclofen has no acute toxicity on adult spider mite females. RNA extraction, cDNA synthesis and qPCR conditions were performed as written above.

To determine CCEO4 copy number, pooled adult mites were homogenized in $800 \mu 1$ SDS buffer (2\% SDS, 200 mM Tris-HCl, 400 mM NaCl, 10 mM EDTA, pH = 8.33), followed by DNA extraction using the phenol-chloroform method. ${ }^{49}$ Before extraction, homogenates were treated with proteinase $\mathrm{K}(20 \mathrm{mg} / \mathrm{mL})$ and RNase A $(10 \mathrm{mg} / \mathrm{mL})$. DNA was precipitated with isopropanol and the DNA pellet was washed with $70 \%$ cold 
ethanol, after which it was re-suspended in $1 \mathrm{mM}$ Tris, $\mathrm{pH}$ 8.0. DNA was quantified using the NanoDrop ND-1000 spectrophotometer (Nanodrop Technologies). Exactly 10 ng of genomic DNA (gDNA) was used in the qPCR experiment. Ubiquitin (tetur03g06910) actin and rp49 were used as reference genes and primer sequences are shown in Table S1 and Figure S1.

\subsection{Restriction fragment length polymorphism (RFLP) on genomic DNA of pooled and single mite samples}

Approximately 300 adult females from resistant and susceptible strains were collected and homogenized in $800 \mu \mathrm{l}$ SDS buffer (2\% SDS, $200 \mathrm{mM}$ Tris-HCl, $400 \mathrm{mM} \mathrm{NaCl}, 10$ $\mathrm{mM}$ EDTA, $\mathrm{pH}=8.33$ ), followed by DNA extraction using the phenol-chloroform method ${ }^{49}$ as described above. PCR reactions were carried out in a Biometra $\mathrm{T}$ professional thermocycler (Biometra) using $1 \mu \mathrm{l}$ DNA as template. A pair of primers (RFLP_F and RFLP_R) were designed to amplify a $961 \mathrm{bp}$ fragment of the CCE04 gene and are listed in Table S1. Reactions were performed in $50 \mu$, containing $20 \mathrm{mM}$ $\mathrm{MgCl} 2,10$ x PCR buffer, $0.2 \mathrm{mM}$ dNTP mix, $1 \mathrm{U}$ taq polymerase (Invitrogen) and 0.2 $\mu \mathrm{M}$ of each primer. PCR conditions were as followed: 2 min at $94{ }^{\circ} \mathrm{C} ; 35$ cycles of 20 s at $94{ }^{\circ} \mathrm{C}, 30 \mathrm{~s}$ at $56{ }^{\circ} \mathrm{C}$ and $30 \mathrm{~s}$ at $72{ }^{\circ} \mathrm{C}$; and a final extension step of $5 \mathrm{~min}$ at $72{ }^{\circ} \mathrm{C}$. PCR products were purified with the E.Z.N.A. Cycle Pure kit (Omega Biotek), followed by Nanodrop quantification (Nanodrop technologies). RFLP was performed on 200 ng PCR product with $1 \mu \mathrm{l}$ BamH1 (New England Biolabs), $2 \mu \mathrm{l}$ NEBuffer and $2 \mu \mathrm{l}$ BSA. The mixture was incubated at $37{ }^{\circ} \mathrm{C}$ for $1 \mathrm{~h}$ and results were analyzed with agarose $(2 \%)$ gel electrophoresis. For single mite analysis of a spirodiclofen resistant strain, eight SRTK males were homogenized in $20 \mu \mathrm{l}$ buffer $(10 \mathrm{mM}$ Tris- $\mathrm{HCl}, 100 \mathrm{mM} \mathrm{NaCl}, 1 \mathrm{mM}$ EDTA $)$ and $2 \mu 1$ proteinase $\mathrm{K}(10 \mathrm{mg} / \mathrm{ml})$ to extract DNA. Samples were incubated in a 
warm water bath at $37{ }^{\circ} \mathrm{C}$ for $30 \mathrm{~min}$, followed by $5 \mathrm{~min}$ at $95{ }^{\circ} \mathrm{C}$ to deactivate proteinase K. PCR reactions and RFLP analysis were performed as written above.

\subsection{Recombinant expression of CCE04 in Pichia pastoris.}

Both $C C E 04$ alleles, $C C E 04^{L o n d o n}$ and $C C E O 4^{S R-V P}$, were codon optimized for yeast expression by GenScript (USA) and sequences encoding a signal peptide were removed (see Figure S2). Both alleles were first cloned in the pUC-57 vector and subcloned in pPICZ $\alpha \mathrm{A}$ via double digest with EcoRI and XbaI. The pPICZ $\alpha \mathrm{A}$ vector carries the methanol inducible expression promoter $\mathrm{P}_{\mathrm{AOX} 1}$ and a signal peptide for protein secretion. The recombinant plasmids were named pPICZ $\alpha \mathrm{A}-\mathrm{CCE}$ 04-London (London-specific allele) and pPICZaA-CCE04-SR-VP (SR-VP-specific allele).

Generation of Pichia competent cells and overall procedures in preparation, electroporation, and colony screening were conducted according to De Schutter et al. ${ }^{50}$ In brief, electro-competent X-33 $P$. pastoris cells were transformed with $0.1 \mu \mathrm{g}$ of linearized recombinant vector using a Gene Pulser II (Bio-Rad) electroporation device with the conditions set at $1.5 \mathrm{kV}, 200 \Omega, 25 \mu \mathrm{F}$ in a $0.2 \mathrm{~cm}$ electroporation cuvette (BioRad). Immediately after electroporation, $1 \mathrm{~mL}$ of cold sorbitol (1M) was added and cells were incubated at $30^{\circ} \mathrm{C}$ for $1 \mathrm{~h}$ with shaking before selection of transformed cells on YPD plates (1\% yeast extract, $2 \%$ peptone, $2 \%$ dextrose, $2 \%$ agar) containing $0.1 \%$ Zeocin (Thermo Fisher Scientific). Production of the recombinant CCE04 alleles was analyzed in 22 randomly selected colonies by Western blot analysis as previously described $^{51}$ and the best producing colonies were selected for further production. For the large scale production, the selected $P$. pastoris $\mathrm{X}-33$ strains containing the pPICZ $\alpha \mathrm{A}$ CCE04-London or pPICZ $\alpha$ A-CCE04-SR-VP constructs were inoculated in 1L BMGY medium (1\% yeast extract; $2 \%$ peptone; $1.34 \%$ yeast nitrogen base with ammonium 
sulfate and without amino acids; $100 \mathrm{mM}$ potassium sulfate, $\mathrm{pH6} ; 1 \%$ glycerol) and grown at $30^{\circ} \mathrm{C}$ while shaking, after $48 \mathrm{~h}$, cells were harvested and resuspended in $1 \mathrm{~L}$ BMMY medium (1\% yeast extract; $2 \%$ peptone; $1.34 \%$ yeast nitrogen base with ammonium sulfate and without amino acids; $100 \mathrm{mM}$ potassium sulfate, $\mathrm{pH} 6 ; 1 \%$ methanol) to induce protein production. During $48 \mathrm{~h}, 1 \%$ methanol was spiked into the medium every $12 \mathrm{~h}$. After centrifugation, the medium proteins were overnight precipitated with $80 \%$ ammonium sulfate at $8^{\circ} \mathrm{C}$. After dissolving the condensed proteins into $0.1 \mathrm{M}$ PBS $\mathrm{pH}$ 7.4, they were desalted by using a Pierce ${ }^{\mathrm{TM}}$ Protein Concentrator (30kd, 5-20mL, Thermofisher). The desalted proteins were passed through a $10 \mathrm{~mL}$ Ni-NTA column (Qiagen), and then washed with PBS buffer containing different concentrations of imidazole (from $25 \mathrm{mM}$ to $250 \mathrm{mM}$ ). The purified protein was analyzed by SDS-PAGE, Western blotting and IEF, as described above.

\subsection{Kinetic analysis and inhibition assays with spirodiclofen and spirodiclofen enol}

Concentrations of both proteins were determined with the Bradford method. ${ }^{52}$ Esterase activities against the model substrates (4-nitrophenyl acetate (4-NPA), 4-nitrophenyl butyrate (4-NPB), 1-naphthyl acetate (1-NA), 1-naphthyl butyrate (1-NB), 2-naphthyl acetate (2-NA) were determined using a 96-well microplate by an Eon microplate spectrophotometer (Biotek, France) as previously described. ${ }^{53}$

Briefly, hydrolytic activities to substrates of 4-NPA and 4-NPB were determined with $5 \mu \mathrm{L}(1 \mu \mathrm{g})$ of enzyme source, $175 \mu \mathrm{L}$ PBS $(0.1 \mathrm{M}, \mathrm{pH} 7.4)$ and $20 \mu \mathrm{L}$ of substrate (concentration in the well ranging from $75 \mu \mathrm{M}$ to $2400 \mu \mathrm{M})$ in $10 \%$ acetone $(200 \mu \mathrm{L}$ reaction volume in total). The rate of 4-nitrophenol formation was measured at $405 \mathrm{~nm}$ kinetically (15 s interval for a 3 min incubation period) using an Eon microplate spectrophotometer (BioTek, France). Reaction rates were adjusted by spontaneous 4nitrophenol formation of control without enzyme. Each reaction was repeated 3 times. 
1-NA and 1-NB of esterase activities were determined by mixing $5 \mu \mathrm{L}(1 \mu \mathrm{g})$ of enzyme source, $155 \mu \mathrm{L}$ of PBS buffer $(0.1 \mathrm{M}, \mathrm{pH} 7.4)$ and $20 \mu \mathrm{L}$ of fresh $1.5 \mathrm{~g} / \mathrm{L}$ filtered fast blue RR solution. The reaction was started by adding $20 \mu \mathrm{L}$ of a 1-NA and 1-NB solution in $10 \%$ acetone. The formation of the 1-naphthol-fast blue RR complex was measured as above at $500 \mathrm{~nm}$. 2-NA and 2-NB of esterase assays were conducted in a similar method as 1-NA and 1-NB except replacement of fast blue RR salt to fast blue B salt. The formation of the 2-naphthol-fast blue B complex was measured as above at $525 \mathrm{~nm}$. Reaction rates were adjusted for spontaneous hydrolysis in control reactions without enzyme. Each reaction was repeated 3 times

The parameters $K_{m}$ and $\mathrm{V}_{\max }$ were estimated from a Michaelis-Menten curve using Graphpad PRISM 5.0 software, and the statistical analysis was executed using an extrasum-of-squares $\mathrm{F}$ test $(p<0.05)$.

In order to assess whether spirodiclofen and spirodiclofen enol interact with the recombinant CCE04 isoforms, we performed inhibition assays. Protein amounts resulting in comparable activity were used for both alleles. The reaction consisted of 5 $\mu \mathrm{L}$ enzyme source, $155 \mu \mathrm{L}$ PBS (0.1M, $\mathrm{pH} 7.0), 10 \mu \mathrm{L}$ substrate (1-NA diluted in $10 \%$ methanol, with final concentration of $18.75 \mu \mathrm{M}$ ) and $10 \mu \mathrm{L}$ spirodiclofen (diluted in $10 \%$ methanol, with final concentration of $100 \mu \mathrm{M})$. The control reaction consisted of 5 $\mu \mathrm{L}$ enzyme source, $155 \mu \mathrm{L} 0.1 \mathrm{M}$ PBS $(0.1 \mathrm{M}, \mathrm{pH} 7.0)$ and $10 \mu \mathrm{L}$ substrate (1-NA diluted in $10 \%$ methanol, with final concentration of $18.75 \mu \mathrm{M})$. The mixtures were incubated for $5 \mathrm{~min}$ at $30{ }^{\circ} \mathrm{C}$ before stop solution (3.6\% SDS) and Fast blue B salt were added. The formation of the 1-naphthol-fast blue B complex was measured as above at $500 \mathrm{~nm}$. There were three replicates for each reaction. The student t-test was adopted to calculate the statistical difference between control and test group $(p<0.05)$.

\section{Results}




\subsection{Microarray analysis and validation}

The gene expression microarray data from spirodiclofen susceptible and resistant strains has been previously described. ${ }^{11}$ According to the microarray expression analysis a gene coding for a carboxyl/choline esterase, tetur01g10750 (CCE04), was highly overexpressed in both resistant strains ( $\sim 34$-fold for SR-VP and $\sim 92$-fold for SR-TK). A BLASTn analysis was conducted with CCEO4 probes against the complete CCE geneset, revealing a potential cross-hybridization risk with two other CCE genes, CCE05 (tetur01g10760) and CCE12 (tetur01g14180). Hence, RT-qPCR was performed using gene-specific primers for CCEO4 (CCE04-3'end primers), CCE05 and CCE12 (Table S1). CCE12 was slightly, but significantly, upregulated, while the expression of CCE05 was downregulated (Fig. 1(a)), indicating that these genes are probably not those identified by the microarray experiment. Remarkably, amplification with gene-specific CCE04-3'end primers (Table S1) did not confirm overexpression of this gene, although it was predicted as the most overexpressed gene by microarray analysis. ${ }^{11} \mathrm{We}$ consequently re-designed a primer pair that matched a part of the gene that is also targeted by two microarray probes (CCE04-inprobe primers; Table S1, Figure S1). RTqPCR with this primer pair confirmed high levels of overexpression of CCE04 in both resistant strains ( 198-fold for SR-VP and 510-fold for SR-TK, Fig. 1). In conclusion, microarray analysis revealed the high overexpression of a CCE, which was confirmed by RT-qPCR. However, the identity of the CCE gene was still unclear, as gene specific primers based on CCE genes annotated in the London genome, failed to correctly identify the highly expressed CCE gene.

\subsection{Iso-electric focusing (IEF) of T. urticae esterases}

To further confirm that a CCE was overexpressed in both resistant strains, we performed an IEF analysis on protein samples of several spider-mite strains. Results 
indicated the presence of an esterase band of very high intensity in both spirodiclofen resistant strains (SR-VP and SR-TK) (Fig. 2) compared to the spirodiclofen susceptible LS-VL strain (used as parental strain for generating the spirodiclofen strain SR-VP) and the London strain. We then further tested if we could detect a similar band in several characterized resistant strains in our laboratory collection that were known to be susceptible to spirodiclofen (MR-VL, MR-VP, BR-VL and Akita). In none of these strains, a similar esterase band pattern was obtained, suggesting that the extra esterase activity zone in SR-VP and SR-TK is specific and potentially associated with spirodiclofen selection (Fig. 2). In any case, these biochemical assays point towards the increased expression of an esterase, thereby further supporting gene expression analysis.

\subsection{RACE analysis and identification of CCEO4 alleles}

Both CCE04-3'end and CCE04-inprobe primers, used for microarray validation, were designed using the CCEO4 sequence of the susceptible London strain, available after sequencing the complete $T$. urticae genome. ${ }^{37}$ However, expression analysis with CCE04-3'end primers did not show overexpression of CCEO4 while analysis with CCE04-inprobe primers showed high levels of overexpression, indicating a difference in sequence. One of the hypotheses to explain this observation, is that there is a CCE gene in the spirodiclofen resistant strains, that shares sequence similarity with CCE04, but is not present in the London genome. Consequently, we performed RACE PCR on cDNA with a nested gene specific primer (Table S1) located inside the sequence of the microarray probe, to sequence and clone the complete CCEO4 of the resistant line. RACE reactions picked up the nucleotide sequences of different clones that were aligned to the London CCEO4 sequence. Sequence analysis revealed the existence of two CCEO4 alleles in the resistant strain. One allele was identical to the CCE04 sequence of the London genome $\left(C C E O 4^{\text {London }}\right)$, while the other allele showed multiple 
SNPs $\left(C C E 04^{S R-V P}\right.$, File S1). The resistant allele codes for a protein with multiple amino acid substitutions compared to the wild type CCE04 protein. Some of these substitutions are located next to the catalytic triad ${ }^{54}$ and, hence, might influence catalytic activity (e.g. F200Y (T. urticae CCE04 numbering) near the serine residue or E439R near the histidine residue) (Figure S2).

\subsection{Expression analysis of $\mathrm{CCEO4}$ in different life stages of $T$. urticae and after induction with spirodiclofen}

We performed RT-qPCR analysis with the CCE04-inprobe primers (see 3.1) on cDNA of embryos, larvae, deutonymph stages and adults in the resistant strain. Expression of CCEO4 is much lower in embryos compared to mobile stages, does not vary between immature stages but is significantly higher in adults (Fig. 1(b)). Induction experiments revealed that the SR-VP specific allele $\left(C C E O 4^{S R-V P}\right)$ is constitutively overexpressed in the spirodiclofen resistant strain and induction by spirodiclofen has little effect on the expression level. In contrast, the London-specific allele $\left(C C E 04^{\text {London }}\right)$ is induced by spirodiclofen treatment in the susceptible LS-VL strain (Fig. 3).

\subsection{RFLP analysis of CCE04 from resistant and susceptible strains}

To screen the resistant and susceptible strains for the presence of both alleles, and potentially obtain a diagnostic marker, we designed and performed an RFLP analysis. A CCE04 fragment of approximately $961 \mathrm{bp}$ was generated by amplification of gDNA of pooled mites from SR-VP, SR-TK, LS-VL and London. BamHI recognizes and cuts the sequence $\mathrm{G}^{\wedge} \mathrm{GATCC}$, which is absent in the London-specific CCEO4 allele but present in the SR-VP-specific CCEO4 allele. We observed two digestion patterns: one pattern represents the uncut, non-digested fragment at $963 \mathrm{bp}$ and is only visible in the susceptible London population; the second pattern shows 3 bands, the original uncut 
fragment and the digested fragments (388 bp and $573 \mathrm{bp}$ ), and is present in SR-VP, SRTK and LS-VL (Figure S3). Restriction digest are thus in line with RACE experiments and strongly suggested that both the London and SR-VP specific allele are present in the resistant strains. The presence of both alleles in resistant strains could in principle also be due to incomplete digestion, as outlined by Osakabe et al. ${ }^{55}$. However, an RFLP analysis on single (haploid) males from a spirodiclofen resistant strain (SR-TK), revealed that only one allele $\left(C C E O 4^{S R-V P}\right.$ (two fragments) or $C C E 04^{\text {London }}$ (uncut fragment)) is present in a single male (Figure S4). Analysis also suggested that the resistant allele $\left(C C E O 4^{S R-V P}\right)$ was enriched during spirodiclofen selection with LS-VL, as it could indeed be identified in LS-VL (at low levels) but not in the unrelated reference London strain (Figure S3).

\subsection{CCE04 copy number determination}

We further investigated whether both CCEO4 sequences represent duplicated loci or are alleles of a single locus. We first performed qPCR on gDNA of both the spirodiclofen resistant (SR-VP and SR-TK) and susceptible strains (LS-VL and London), using unspecific primers that amplify both alleles (CCE04-inprobe) and primer pairs specific for both alleles (see Table S1). CCE04 copy number assessment with unspecific primers of CCEO4 (CCE04-inprobe) did not reveal any difference between strains. However, results with the CCE04-SR-VP primers indicated an enrichment of $C C E O 4^{S R-V P}$ allele, as the $C C E 04^{S R-V P}$ allele was $\sim 540$-fold and $\sim 415$-fold more present in SR-VP and SR-TK, respectively, relative to the London strain. On the other hand, results with the CCE04London primers revealed an opposite pattern for the CCEO4 $4^{\text {London }}$ allele, when compared to the London strain (Fig. 4(a)). Last, a similar CCEO4 ${ }^{S R-V P}$ enrichment pattern was obtained with the CCE04-SR-VP primers when compared to the LS-VL strain, however, only a $\sim 6.6$-fold and $\sim 5.1$-fold of increase of the CCEO4 $4^{S R-V P}$ allele was found in the 
SR-VP and SR-TK strain, respectively, consistent with the presence of the CCEO4 ${ }^{S R-V P}$ allele in the LS-VL population (Fig. 4(b)). Together, this reveals enrichment of alleles rather than gene amplification of the locus.

\subsection{Analysis of $T$. urticae $\mathrm{CCE04}$ and position within CCE phylogeny}

The T. urticae genome of the London strain contains 69 putative full-length CCEs, which is in in line with those reported for other arthropod genomes. ${ }^{21,37}$ However, $T$. urticae has 2 new CCE clades within the neurodevelopmental class ( $\mathrm{J}$ ' and J"), representing 32 and 22 CCEs (Figure S5) ${ }^{37}$, pointing out that the classification as proposed by Oakeshott $2005^{56}$ is less relevant for Acari. Phylogenetic analysis including both CCE04 isoforms [London-specific allele (tetur01g10750, CCE04 ${ }^{\text {London }}$ ) and SR-VP specific allele $\left.\left(\mathrm{CCE} 04^{\mathrm{SR}-\mathrm{VP}}\right)\right]$ reveals a close clustering with tetur01g10740 (CCE03), tetur01g10760 (CCE05) and tetur01g1480 (CCE12) within clade J" of the neurodevelopmental class (Figure S5). Except for CCE19 and CCE67, all members of clade J" contain conserved residues necessary for catalytic activity (serine 200, glutamate 327 and histidine 440 based on Torpedo californica numbering ${ }^{54}$ ) (Figure S2, Table S2 File S2). A signature motif of the esterase family, GxSxG, around the catalytic serine residue is present in both clade $\mathrm{J}$ ' and $\mathrm{J}$ ' (File S2, Table S2). Twenty-four members $(71 \%)$ of the J' clade have the GESAG motif compared to only one member of clade J" (CCE04 of clade J" has a GHSAG motif) (File S2, Table S2). Most members of clade J" (18 out of 22), including CCE04, are predicted to contain a signal peptide (Figure S2, File S2, Table S2), indicating that the majority of the CCEs from the J" clade is secreted. Finally, the ScanProsite tool revealed that both CCE04 isoforms had the PS00941 motif (Carboxylesterases type-B signature 2).

\subsection{Recombinant expression of CCE04 alleles}


To potentially assess different catalytic properties of both alleles, and to test the interaction between spirodiclofen and CCE04, we functionally expressed both alleles $\left(C C E 04^{S R-V P}\right.$ and $\left.C C E 04^{\text {London }}\right)$ using a Pichia based expression system. SDS-PAGE and Western blot analysis revealed that CCE04 was robustly expressed in the transformed yeast cells and secreted into the medium. Only a single band corresponding to an approximate molecular weight of $75 \mathrm{kDa}$ was detected after purification (Figure S6).

Next, the activity of both enzymes was measured towards six model substrates (1-NA, 1-NB, 2-NA, 4-NPA and 4-NPB). The maximum velocities were not significantly different between the two alleles for all substrates (Table 1). Similarly, the MichaelisMenten constants $\left(K_{\mathrm{m}}\right)$ of both enzymes were also not significant for most substrates, but the $K_{\mathrm{m}}$ value of $\mathrm{CCE} 04^{\mathrm{SR}-\mathrm{VP}}(2224 \pm 200.2 \mu \mathrm{M})$ towards $4-\mathrm{NPB}$ was slightly but significantly higher than that of CCE04 $4^{\text {London }}(1757 \pm 94.01 \mu \mathrm{M})($ Table 1$)$.

Furthermore, we tested whether spirodiclofen affected the metabolism of 1-NA, by assessing activity towards this model substrate in the presence of $100 \mu \mathrm{M}$ spirodiclofen, the highest dissolvable concentration in our conditions. The presence of spirodiclofen had an inhibiting effect on the hydrolysis of 1-NA to a similar extent for both CCE04 isoforms (28.69\% of inhibition for CCE0 $4^{\text {London }}$ and $25 \%$ of inhibition for CCE0 $4^{\mathrm{SR}-\mathrm{VP}}$ ). As expected, the already hydrolyzed spirodiclofen enol did not display any inhibition effect on both enzymes (Fig. 5).

\section{Discussion}

A genome-wide microarray comparing overall gene expression of a susceptible and two genetically distinct spirodiclofen resistant strains, SR-VP and SR-TK, revealed the overexpression of several genes, including an esterase (CCE04, tetur01g10750). This 
gene was the highest overexpressed gene identified in both spirodiclofen resistant strains. ${ }^{11}$ However, validating the microarray results with gene specific primers uncovered the probability that a sequence not present in the London genome was linked with resistance, and picked up by the microarray (Fig. 1). RACE-PCR was performed on cDNA of SR-VP and indeed revealed the existence of two closely related CCEO4 sequences, one matching with the CCEO4 sequence of the London genome (named London specific allele, CCE04 ${ }^{\text {London }}$ ) and one with several SNPs scattered over the complete length of the sequence (named SR-VP specific allele, $C C E 04^{S R-V P}$ ) resulting in 31 amino acid substitutions compared to the London-specific allele (Figure S2). Several options were then investigated, as this result could either point towards gene duplication/amplification, or to alternative alleles of the same locus. Amplification of esterase genes is a well-documented mechanism that results in increased expression levels, and was especially well studied in resistant strains of the aphid Myzus persicae and several Culex species resistant to OP compounds. ${ }^{28,57}$ Amplification creates many identical gene copies to fulfill a high expression demand that cannot be reached by a single copy with an active promotor. ${ }^{18}$ In this study, qPCR with allele specific primers revealed that $C C E 04^{S R-V P}$ was 540 -and 6.6 -fold more present in the SR-VP strain compared to the London and LS-VL strain, respectively. Although this could indicate gene amplification, the reverse pattern was found for $C C E 04^{\text {London }}$, and a more likely explanation seems that selection enriched for a specific allele of the same locus. This was also confirmed by qPCR using primers that amplify both alleles (CCE04-inprobe, Fig. 4). In addition, RFLP analysis failed to document the occurrence of both alleles in a haploid male of a spirodiclofen resistant strain (see Figure S4). In silico characterization and phylogenetic analysis suggest that both alleles of CCE04 are functionally active, as they belong to the spider mite specific clade J", of which the majority has all features of 
active (presence of catalytic triad) and secreted (presence of a signal peptide) enzymes (Figure S2, Figure S5). This was also suggested by IEF, where the presence of a highly expressed and active esterase was also biochemically confirmed by native staining in both resistant strains. The specificity of the esterase for spirodiclofen resistant strains was further documented by including several other well-characterized resistant strains, none of which showed the typical band associated with both resistant strains (Fig. 2). Taken all data together, it was concluded that a specific allele of CCEO4 (CCEO4 $\left.{ }^{S R-V P}\right)$ was enriched by selection and associated with spirodiclofen resistance. Furthermore, induction experiments revealed that exposure to spirodiclofen has little effect on the expression level of $\mathrm{CCE} 04^{\mathrm{SR}-\mathrm{VP}}$ in the SR-VP strain, while the expression of CCEO4 $4^{\text {London }}$ was clearly induced by spirodiclofen treatment in the susceptible LS-VL strain (Fig. 3). As such, this might represent an example of genetic assimilation ${ }^{58}$, where the phenotype (esterase activity) in response to a toxin (spirodiclofen) becomes genetically stable by selection. Of particular note, genetic assimilation has been demonstrated before in the spider mite $T$. urticae with respect to host plant adaptation. ${ }^{59}$

Functional enzyme assays, after recombinant expression and purification of both CCE04 isoforms, suggested only limited kinetic difference between different model substrates (Table 1). In addition, the inhibition/competition between spirodiclofen and model substrates indicated that there is a similar interaction of both enzymes with spirodiclofen (Fig. 5). These findings are in line with Hopkins et al. 2017, showing that a sequestering Culex quinquefasciatus CCE (Cqest $\beta 2)$ did not differ significantly from a 15-amino acid differing isoform (Cqest $\beta 1)$ with respect to their interaction with insecticides. $^{60}$ Overall, this suggests that quantitative differences between CCE04 isoforms rather than qualitative differences are more likely involved in spirodiclofen resistance. This has to be discussed in the light of spirodiclofen metabolism, where ester 
hydrolysis activates spirodiclofen to its corresponding enol ${ }^{15}$, and sequestration of spirodiclofen is a likely hypothesis. Overexpression of CCE04 would then bind/sequester the compound and hereby delay the activation to the toxophore. In turn, this delayed activation would then allow CYP392E10 to hydroxylate spirodiclofen to hydroxy-spirodiclofen ${ }^{11}$, which is then spontaneously hydrolyzed to hydroxy spirodiclofen enol, reported to be non-toxic for spider mites (Fig. 6). ${ }^{15}$. Of particular note, expression of $\mathrm{CCEO4}$ was much lower in embryos compared to mobile stages (Fig. 1), which was also observed for P450 genes, and might be related to lack of resistance to spirodiclofen in the embryo stage of spider mites. ${ }^{9,11,15}$

In the case of quantitative differences between alleles, resistance selected not for the specific allele, but for the allele-specific overexpression mechanism. Overexpression of the SR-VP specific allele could be caused by cis- or trans-acting mechanisms. The cisacting mechanism refers to local polymorphisms that influence the synthesis or stability of the same gene, while trans mechanisms have an effect on a different gene. ${ }^{61,62}$ In a recent study, using an SR-VP derived inbred line, spirodiclofen resistance was mapped in high resolution to a number of genomic loci (Quantitative Trait Locus, QTL mapping), confirming its polygenic nature. None of the QTLs was associated with the CCE04 locus (located on pseudochromosome 1 at $2.39 \mathrm{Mb}$ ), but contained other interesting candidate genes: ACCase - the target of keto-enol acaricides (on pseudochromosome 1 at $6.56 \mathrm{Mb}$ ), a region containing P450s (on pseudochromosome 1 at $24.13 \mathrm{Mb}$ ) belonging to the same P450 subfamily as CYP392E10, known to metabolize spirodiclofen ${ }^{11}$ and cytochrome $\mathrm{P} 450$ reductase (CPR) (on pseudochromosome 2 at $5.69 \mathrm{Mb}) .{ }^{13}$ On the other hand, it is still possible that these genomic loci harbor regulators (e.g. transcription factors) that are associated with the potentially fixed $C C E O 4^{S R-V P}$ allele. However, during inbreeding, some of the genetic 
variation is randomly fixed, and it is not sure to what extent investigations of inbred lines do inform correctly on the overall combination of resistance factors. To study cis versus trans regulation and confirm the overall role of the SR-VP allele in resistance, marker assisted back crossing might be considered.

In conclusion, we confirmed the overexpression and association of a specific allele $\left(C C E 04^{S R-V P}\right)$ in two genetically independent spirodiclofen resistant strains. We revealed that selection enriched this specific allele most likely because of associated high expression levels, more than a different enzymatic potential. Given the specific metabolism of spirodiclofen, esterase sequestration combined with CYP392E10 hydroxylation seems more likely. The precise mechanism that leads to the extreme high expression levels is still unclear and deserves further investigation. Nevertheless, the RFLP based diagnostic marker developed here might further assist in strengthening the association between this resistance allele and spirodiclofen resistance.

\section{Acknowledgements}

We thank dr. Luc Swevers (IBA NCSR 'Demokritos', Greece) for guidance during initial CCE04 protein production. This work was supported by the Research Foundation Flanders (FWO) [grant G009312N to TVL and grant G053815N to TVL and WD] and the Research Council (ERC) under the European Union's Horizon 2020 research and innovation program [grant 772026-POLYADAPT to TVL and 773902-SuperPests to TVL and JV]. WD is a post-doctoral fellow of the Research Foundation Flanders (FWO).

\section{References}

1. Van Leeuwen T, Vontas J, Tsagkarakou A, Dermauw W and Tirry L, Acaricide resistance mechanisms in the two-spotted spider mite Tetranychus urticae and other important Acari: a review. Insect Biochem Mol Biol 40: 563-572 (2010). 
2. Van Leeuwen T and Dermauw W, The Molecular Evolution of Xenobiotic Metabolism and Resistance in Chelicerate Mites. Annu Rev Entomol 61: 475-498 (2016).

3. Van Leeuwen T, Tirry L, Yamamoto A, Nauen R and Dermauw W, The economic importance of acaricides in the control of phytophagous mites and an update on recent acaricide mode of action research. Pestic Biochem Physiol 121: 12-21 (2015).

4. Wachendorff U, Bruck E, Elbert A, Fischer R, Nauen R, Stumpf N and Tiemann R. BAJ2740, a novel broad spectrum acaricide. In Brighton Crop Protection Conference: Pests \& Diseases 2000, Vols 1-3, Proceedings. British Crop Protection Council: Farnham, pp. 53-58 (2000).

5. Lümmen $P$, Khajehali J, Luther $\mathrm{K}$ and Van Leeuwen $\mathrm{T}$, The cyclic keto-enol insecticide spirotetramat inhibits insect and spider mite acetyl-CoA carboxylases by interfering with the carboxyltransferase partial reaction. Insect Biochem Mol Biol 55: 1-8 (2014).

6. Wu M, Adesanya AW, Morales MA, Walsh DB, Lavine LC, Lavine MD and Zhu F, Multiple acaricide resistance and underlying mechanisms in Tetranychus urticae on hops. J Pest Sci 92: 543-555 (2018).

7. Ferreira CBS, Andrade FHN, Rodrigues ARS, Siqueira HAA and Gondim MGC, Resistance in field populations of Tetranychus urticae to acaricides and characterization of the inheritance of abamectin resistance. Crop Prot 67: 77-83 (2015).

8. Kramer T and Nauen R, Monitoring of spirodiclofen susceptibility in field populations of European red mites, Panonychus ulmi (Koch) (Acari: Tetranychidae), and the crossresistance pattern of a laboratory-selected strain. Pest Manag Sci 67: 1285-1293 (2011).

9. Van Pottelberge S, Van Leeuwen T, Khajehali J and Tirry L, Genetic and biochemical analysis of a laboratory-selected spirodiclofen-resistant strain of Tetranychus urticae Koch (Acari: Tetranychidae). Pest Manag Sci 65: 358-366 (2009).

10. Bajda S, Dermauw W, Greenhalgh R, Nauen R, Tirry L, Clark RM and Van Leeuwen T, Transcriptome profiling of a spirodiclofen susceptible and resistant strain of the European red mite Panonychus ulmi using strand-specific RNA-seq. BMC Genomics 16: 974 (2015).

11. Demaeght P, Dermauw W, Tsakireli D, Khajehali J, Nauen R, Tirry L, Vontas J, Lummen $P$ and Van Leeuwen T, Molecular analysis of resistance to acaricidal spirocyclic tetronic acids in Tetranychus urticae: CYP392E10 metabolizes spirodiclofen, but not its corresponding enol. Insect Biochem Mol Biol 43: 544-554 (2013).

12. Van Pottelberge S, Van Leeuwen T, Khajehali J and Tirry L, Genetic and biochemical analysis of a laboratory-selected spirodiclofen-resistant strain of Tetranychus urticae Koch (Acari: Tetranychidae). Pest Manag Sci 65: 358-366 (2009).

13. Wybouw N, Kosterlitz O, Kurlovs AH, Bajda S, Greenhalgh R, Snoeck S, Bui H, Bryon A, Dermauw W, Van Leeuwen T and Clark RM, Long-Term Population Studies Uncover the Genome Structure and Genetic Basis of Xenobiotic and Host Plant Adaptation in the Herbivore Tetranychus urticae. Genetics 211: 1409-1427 (2019).

14. Nauen R, Spirodiclofen: Mode of action and resistance risk assessment in tetranychid pest mites. J Pestic Sci 30: 272-274 (2005).

15. Rauch $\mathrm{N}$ and Nauen $\mathrm{R}$, Spirodiclofen resistance risk assessment in Tetranychus urticae (Acari: Tetranychidae): a biochemical approach. Pestic Biochem Physiol 74: 91-101 (2002).

16. Farahani S, Bandani A and Eslami S, Comparison of susceptibility of two Iranian populations of Tetranychus urticae Koch (Acari: Tetranychidae) to spirodiclofen. Persian Journal of Acarology 7: 279-287 (2018).

17. Li X, Schuler MA and Berenbaum MR, Molecular mechanisms of metabolic resistance to synthetic and natural xenobiotics. Annu Rev Entomol 52: 231-253 (2007).

18. Feyereisen R, Molecular biology of insecticide resistance. Toxicol Lett 82: 83-90 (1995). 
19. Hemingway J and Karunaratne S, Mosquito carboxylesterases: a review of the molecular biology and biochemistry of a major insecticide resistance mechanism. Med Vet Entomol 12: 1-12 (1998).

20. Wheelock CE, Shan $\mathrm{G}$ and Ottea J, Overview of carboxylesterases and their role in the metabolism of insecticides. J Pestic Sci 30: 75-83 (2005).

21. Oakeshott J, Claudianos C, Campbell P, Newcomb R and Russell R. Biochemical genetics and genomics of insect esterases. In Insect pharmacology: Channels, receptors, toxins and enzymes, ed. by Gilbert LI and Gill SS. Elsevier: London, U.K. (2005).

22. Devorshak $\mathrm{C}$ and Roe $\mathrm{R}$, The role of esterases in insecticide resistance. Reviews in Toxicology 2: 501-537 (1999).

23. Aldridge WN, Serum esterases. I. Two types of esterase (A and B) hydrolysing $p$ nitrophenyl acetate, propionate and butyrate, and a method for their determination. Biochem J 1: 110-117 (1953).

24. Aldridge WN and Reiner E. Enzyme inhibitors as substrates : interactions of esterases with esters of organophosphorus and carbamic acids. North Holland, (1972).

25. Yu Q-Y, Lu C, Li W-L, Xiang Z-H and Zhang Z, Annotation and expression of carboxylesterases in the silkworm, Bombyx mori. BMC Genomics 10: 553 (2009).

26. Teese MG, Campbell PM, Scott C, Gordon KHJ, Southon A, Hovan D, Robin C, Russell RJ and Oakeshott JG, Gene identification and proteomic analysis of the esterases of the cotton bollworm, Helicoverpa armigera. Insect Biochem Mol Biol 40: 1-16 (2010).

27. Hemingway J, The molecular basis of two contrasting metabolic mechanisms of insecticide resistance. Insect Biochem Molec 30: 1009-1015 (2000).

28. Bass C and Field LM, Gene amplification and insecticide resistance. Pest Manag Sci 67: 886-890 (2011).

29. Grigoraki L, Balabanidou V, Meristoudis C, Miridakis A, Ranson H, Swevers L and Vontas J, Functional and immunohistochemical characterization of CCEae3a, a carboxylesterase associated with temephos resistance in the major arbovirus vectors Aedes aegypti and Ae. albopictus. Insect Biochem Mol Biol 74: 61-67 (2016).

30. Li Y, Farnsworth CA, Coppin CW, Teese MG, Liu J-W, Scott C, Zhang X, Russell RJ and Oakeshott JG, Organophosphate and pyrethroid hydrolase activities of mutant esterases from the cotton bollworm Helicoverpa armigera. PLoS One 8: e77685 (2013).

31. Claudianos C, Russell RJ and Oakeshott JG, The same amino acid substitution in orthologous esterases confers organophosphate resistance on the house fly and a blowfly. Insect Biochem Mol Biol 29: 675-686 (1999).

32. Campbell PM, Newcomb RD, Russell RJ and Oakeshott JG, Two different amino acid substitutions in the ali-esterase, E3, confer alternative types of organophosphorus insecticide resistance in the sheep blowfly, Lucilia cuprina. Insect Biochem Mol Biol 28: 139-150 (1998).

33. Van Leeuwen $T$, Stillatus V and Tirry L, Genetic analysis and cross-resistance spectrum of a laboratory-selected chlorfenapyr resistant strain of two-spotted spider mite (Acari: Tetranychidae). Exp Appl Acarol 32: 249-261 (2004).

34. Van Leeuwen T and Tirry L, Esterase-mediated bifenthrin resistance in a multiresistant strain of the two-spotted spider mite, Tetranychus urticae. Pest Manag Sci 63: 150-156 (2007).

35. Wei P, Li J, Liu X, Nan C, Shi L, Zhang Y, Li C and He L, Functional analysis of four upregulated carboxylesterase genes associated with fenpropathrin resistance in Tetranychus cinnabarinus (Boisduval). Pest Manag Sci 75: 252-261 (2019).

36. Wei P, Chen M, Nan C, Feng K, Shen G, Cheng J and He L, Downregulation of carboxylesterase contributes to cyflumetofen resistance in Tetranychus cinnabarinus (Boisduval). Pest Manag Sci: doi: 10.1002/ps.5339 (2019).

37. Grbić M, Van Leeuwen T, Clark RM, Rombauts S, Rouzé P, Grbić V, Osborne EJ, Dermauw W, Thi Ngoc PC, Ortego F, Hernández-Crespo P, Diaz I, Martinez M, Navajas 
M, Sucena É, Magalhães S, Nagy L, Pace RM, Djuranović S, Smagghe G, Iga M, Christiaens O, Veenstra JA, Ewer J, Villalobos RM, Hutter JL, Hudson SD, Velez M, Yi SV, Zeng J, Pires-daSilva A, Roch F, Cazaux M, Navarro M, Zhurov V, Acevedo G, Bjelica A, Fawcett JA, Bonnet E, Martens C, Baele G, Wissler L, Sanchez-Rodriguez A, Tirry L, Blais C, Demeestere K, Henz SR, Gregory TR, Mathieu J, Verdon L, Farinelli L, Schmutz J, Lindquist $\mathrm{E}$, Feyereisen $\mathrm{R}$ and Van de Peer $\mathrm{Y}$, The genome of Tetranychus urticae reveals herbivorous pest adaptations. Nature 479: 487 (2011).

38. Van Leeuwen $\mathrm{T}$, Van Pottelberge $\mathrm{S}$ and Tirry L, Comparative acaricide susceptibility and detoxifying enzyme activities in field-collected resistant and susceptible strains of Tetranychus urticae. Pest Manag Sci 61: 499-507 (2005).

39. Van Pottelberge $S$, Van Leeuwen $T$, Nauen R and Tirry L, Resistance mechanisms to mitochondrial electron transport inhibitors in a field-collected strain of Tetranychus urticae Koch (Acari: Tetranychidae). Bull Entomol Res 99: 23-31 (2009).

40. Van Leeuwen $T$, Tirry $L$ and Nauen R, Complete maternal inheritance of bifenazate resistance in Tetranychus urticae Koch (Acari: Tetranychidae) and its implications in mode of action considerations. Insect Biochem Mol Biol 36: 869-877 (2006).

41. Pfaffl MW, Horgan GW and Dempfle L, Relative expression software tool (REST@) for group-wise comparison and statistical analysis of relative expression results in realtime PCR. Nucleic Acids Res 30: e36-e36 (2002).

42. Petersen TN, Brunak S, von Heijne $G$ and Nielsen H, SignalP 4.0: discriminating signal peptides from transmembrane regions. Nat Meth 8: 785 (2011).

43. Claudianos $C$, Ranson $H$, Johnson R, Biswas S, Schuler M, Berenbaum M, Feyereisen $R$ and Oakeshott J, A deficit of detoxification enzymes: pesticide sensitivity and environmental response in the honeybee. Insect Mol Biol 15: 615-636 (2006).

44. Katoh K, Rozewicki J and Yamada KD, MAFFT online service: multiple sequence alignment, interactive sequence choice and visualization. Brief Bioinform: bbx108 (2017).

45. Miller MA, Pfeiffer W and Schwartz T. Creating the CIPRES Science Gateway for inference of large phylogenetic trees. In 2010 Gateway Computing Environments Workshop (GCE), pp. 1-8 (2010).

46. Stamatakis A, RAxML version 8: a tool for phylogenetic analysis and post-analysis of large phylogenies. Bioinformatics 30: 1312-1313 (2014).

47. Tamura K, Stecher G, Peterson D, Filipski A and Kumar S, MEGA6: Molecular Evolutionary Genetics Analysis Version 6.0. Mol Biol Evol 30: 2725-2729 (2013).

48. Van Pottelberge S, Khajehali J, Van Leeuwen T and Tirry L, Effects of spirodiclofen on reproduction in a susceptible and resistant strain of Tetranychus urticae (Acari: Tetranychidae). Exp Appl Acarol 47: 301-309 (2009).

49. Sambrook J, Russell DW and Russell DW. Molecular cloning: a laboratory manual (3volume set). Cold spring harbor laboratory press Cold Spring Harbor, New York:, (2001).

50. De Schutter K and Callewaert N. Pichia Surface Display: A Tool for Screening Single Domain Antibodies. In Single Domain Antibodies: Methods and Protocols, ed. by Saerens D and Muyldermans S. Humana Press: Totowa, NJ, pp. 125-134 (2012).

51. Wybouw N, Balabanidou V, Ballhorn DJ, Dermauw W, Grbić M, Vontas J and Van Leeuwen T, A horizontally transferred cyanase gene in the spider mite Tetranychus urticae is involved in cyanate metabolism and is differentially expressed upon host plant change. Insect Biochem Mol Biol 42: 881-889 (2012).

52. Bradford MM, A rapid and sensitive method for the quantitation of microgram quantities of protein utilizing the principle of protein-dye binding. Anal Biochem $\mathbf{7 2}$ 248-254 (1976).

53. Van Leeuwen $\mathrm{T}$, Van Pottelberge $\mathrm{S}$ and Tirry L, Biochemical analysis of a chlorfenapyrselected resistant strain of Tetranychus urticae Koch. Pest Manag Sci 62: 425-433 (2006). 
54. Sussman JL, Harel M, ., Frolow F, ., Oefner C, ., Goldman A, ., Toker L, . and Silman I, . Atomic structure of acetylcholinesterase from Torpedo californica: a prototypic acetylcholine-binding protein. Science 253: 872-879 (1991).

55. Osakabe M, Imamura T, Nakano R, Kamikawa S, Tadatsu M, Kunimoto $\mathrm{Y}$ and Doi M, Combination of restriction endonuclease digestion with the $\Delta \Delta \mathrm{Ct}$ method in real-time PCR to monitor etoxazole resistance allele frequency in the two-spotted spider mite. Pestic Biochem Physiol 139: 1-8 (2017).

56. Oakeshott JG CC, Campbell PM, Newcomb RD, Russell RJ, Biochemical genetics and genomics of insect esterases. Comprehensive molecular insect science - pharmacology 5: 309-381 (2005).

57. Raymond M, Chevillon C, Guillemaud T, Lenormand T and Pasteur N, An overview of the evolution of overproduced esterases in the mosquito Culex pipiens. Philosophical Transactions of the Royal Society of London Series B: Biological Sciences 353: 17071711 (1998).

58. Pigliucci $\mathrm{M}$, Murren $\mathrm{CJ}$ and Schlichting $\mathrm{CD}$, Phenotypic plasticity and evolution by genetic assimilation. J Exp Biol 209: 2362 (2006).

59. Wybouw N, Zhurov V, Martel C, Bruinsma KA, Hendrickx F, Grbić V and Van Leeuwen T, Adaptation of a polyphagous herbivore to a novel host plant extensively shapes the transcriptome of herbivore and host. Mol Ecol 24: 4647-4663 (2015).

60. Hopkins DH, Fraser NJ, Mabbitt PD, Carr PD, Oakeshott JG and Jackson CJ, Structure of an insecticide sequestering carboxylesterase from the disease vector Culex quinquefasciatus: What makes an enzyme a good insecticide sponge? Biochemistry 56 5512-5525 (2017).

61. Doss S, Schadt EE, Drake TA and Lusis AJ, Cis-acting expression quantitative trait loci in mice. Genome research 15: 681-691 (2005).

62. Ciobanu DC, Lu L, Mozhui K, Wang X, Jagalur M, Morris JA, Taylor WL, Dietz K, Simon P and Williams RW, Detection, validation, and downstream analysis of allelic variation in gene expression. Genetics 184: 119-128 (2010).

63. Lenfant $\mathrm{N}$, Hotelier $\mathrm{T}$, Velluet $\mathrm{E}$, Bourne $\mathrm{Y}$, Marchot $\mathrm{P}$ and Chatonnet $\mathrm{A}, \mathrm{ESTHER}$, the database of the $\alpha / \beta$-hydrolase fold superfamily of proteins: tools to explore diversity of functions. Nucleic Acids Res 41: D423-D429 (2013).

\section{Tables}

Table 1 - Kinetic parameters of $\mathrm{CCEO4}^{\text {London }}$ and $\mathrm{CCEO4}^{\mathrm{SR}-\mathrm{VP}}$ for different substrates. An asterisk indicates a significant difference between the two alleles.

\begin{tabular}{|c|c|c|c|c|}
\hline & \multicolumn{2}{|l|}{$K_{m} \pm \mathrm{SE}(\mu \mathrm{M})$} & \multicolumn{2}{|c|}{$\mathrm{V}_{\max } \pm \mathrm{SE}(\mathrm{mOD} / \mathrm{min} / \mu \mathrm{g})$} \\
\hline & $\mathrm{CCE} 04^{\text {London }}$ & $\mathrm{CCE} 04^{\mathrm{SR}-\mathrm{VP}}$ & CCE04 $4^{\text {London }}$ & $\mathrm{CCE} 04^{\mathrm{SR}-\mathrm{VP}}$ \\
\hline $1-\mathrm{NA}$ & $1193 \pm 106.3$ & $1717 \pm 287.0$ & $322.3 \pm 13.8$ & $335.3 \pm 30.34$ \\
\hline $1-\mathrm{NB}$ & $400.2 \pm 82.10$ & $412.6 \pm 88.69$ & $600.4 \pm 66.39$ & $429.1 \pm 50.30$ \\
\hline 2-NA & $334.4 \pm 46.96$ & $366.0 \pm 58.94$ & $548.7 \pm 24.87$ & $573.0 \pm 30.59$ \\
\hline
\end{tabular}




\section{Figure Legends}

Figure 1 - RT-qPCR validation of $C C E 04$ expression in spirodiclofen resistant strains SR-VP and SR-TK and stage specific expression of CCEO4 in the SR-VP strain (a) RT-qPCR validation of microarray results was performed for three esterase gene candidates: CCE04, CCEO5 and CCE12. CCE04-3'end primers did not result in overexpression of the corresponding gene. However, amplification with CCE04-inprobe primers lead to high values of overexpression, validating microarray results. n.d.: amplification by CCE043 'end primers was not determined for the SR-TK strain (b) Expression of CCEO4 (using CCE04-inprobe primers) in different life stages of the SR-VP strain, relative to their expression in embryos. L: larvae, DN: deutonymph and A: adult. Error bars represent the standard error of the calculated mean based on three biological replicates. Asterisks indicate whether expression is significantly different based on Pfaffl analysis.

Figure 2 - IEF gel stained for esterases. (a) Esterase profile of spirodiclofen susceptible (S: LS-VL and London) and resistant (R: SR-VP and SR-TK) adult females (left) and nymphs (right). A red arrow indicates an esterase band with high intensity in adults and nymphs of the resistant strains, while a black arrow indicates a shared esterase band present in both susceptible and resistant strains. The SR-VP strain was selected from the spirodiclofen susceptible LS-VL strain (b) Esterase profile of adult females of different multi-resistant strains. The esterase band with high intensity, indicated by a red arrow, specific for spirodiclofen resistant strain SR-VP, is not present in other strains. 
Figure 3 - Induction of $C C E 04^{S R-V P}$ and $C C E 04^{L o n d o n}$ expression. Induction of $C C E 04^{S R-V P}$ and $C C E 04^{\text {London }}$ expression after treatment with spirodiclofen, compared to the untreated reference strain (LS-VL not-induced). Error bars represent the standard error of the calculated mean based on three biological replicates. Asterisks indicate whether expression is significantly different based on Pfaffl analysis.

Figure 4 - CCE04 copy number assessment. (a) CCE04 copy number assessment on gDNA, relative to the susceptible London strain. (b) CCEO4 copy number assessment on gDNA, relative to the susceptible strain LS-VL. CCE04 copy number was assessed using CCE04-inprobe primers, while CCEO4 ${ }^{\text {London }}$ and $C C E 04^{S R-V P}$ copy number was assessed using CCE04-London and CCE04-SRVP primers, respectively. Error bars represent the standard error of the calculated mean based on three biological replicates. Asterisks indicate whether CCE04 copy number is significantly different from London (a) or from LS-VL (b) based on Pfaffl analysis.

Figure 5 - Inhibition assay with $\mathrm{CCEO4}{ }^{\mathrm{London}}$ and $\mathrm{CCEO4}^{\mathrm{SR}-\mathrm{VP}}$ with and without spirodiclofen/spirodiclofen enol. Error bars represent the standard error of the calculated mean based on three replicates. Different letters indicate statistically significant differences. $\triangle \mathrm{OD}$ represents the production of 1-naphthol after an incubation period of $5 \mathrm{~min}$ by measuring at $500 \mathrm{~nm}$.

Figure 6 - Putative spirodiclofen resistance mechanism in $T$. urticae

(a) In spirodiclofen susceptible T. urticae mites spirodiclofen is hydrolyzed into its active form, spirodiclofen enol, which interacts with the carboxyltransferase domain of ACCase ${ }^{5,15}$ (b) In resistant mites spirodiclofen is sequestered by the highly overexpressed CCE04 ${ }^{\mathrm{SR}-\mathrm{VP}}$, preventing ester hydrolysis into spirodiclofen enol. On the other hand, spirodiclofen can be hydroxylated by an overexpressed CYP392E10 (as shown by Demaeght et al. ${ }^{11}$ ) or CYP392E7 (hydroxylation by CYP392E7 could however not be demonstrated in Demaeght et al. as it was not possible to obtain an active CYP392E7 ${ }^{11}$ ) in hydroxy spirodiclofen, which is then hydrolyzed into the non-toxic hydroxy spirodiclofen enol (metabolite 2 in Rauch and Nauen $2002^{15}$ ).

\section{Supplemental Data}

Figure S1 - Position of qPCR primers and microarray probes in the T. urticae CCE04 coding sequence. Alignment of qPCR primer sequences (suffix " F" or " R"; CCE04-3'end, CCE04-inprobe, CCE04-London, CCE04-SR-VP; Table S1) and microarray probe sequences (CUST_124 and CUST_125 in Agilent microarray design $028213^{11}$ ) with the $C C E O 4^{S R-V P}$ and $\bar{C} C E 04^{\text {London }}$ allele.

Figure S2 - Alignment of CCE04 isoforms $\left(\mathrm{CCEO4}^{\mathrm{London}}\right.$ and CCE04 $^{\mathrm{SR}-\mathrm{VP}}$ ). Thirty-one amino acid substitutions can be observed in $\mathrm{CCE} 04^{\mathrm{SR}-\mathrm{VP}}$ compared to $\mathrm{CCE} 04^{\mathrm{London}}$ but none of these are located at positions of catalytic triad residues (serine, 
glutamate and histidine; indicated by red triangles). Predicted signal peptides are shaded gray.

Figure S3 - RFLP analysis on pooled adult females of spirodiclofen resistant and susceptible $T$. urticae strains. The resistant allele is present in two spirodiclofen resistant strains (SR-VP and SR-TK) and in the susceptible strain LS-VL, the parental line of SR-VP. M: molecular weight DNA ladder (lambda).

Figure S4 - RFLP analysis on single T. urticae males of the SR-TK strain. Either the resistant (CCEO4 ${ }^{S R-V P}$, lane; 1,2,4,5,7 and 8) or the susceptible allele $\left(C C E 04^{\text {London }}\right.$, lane 3 and 6) is present in a single male of the SR-TK strain. M: molecular weight DNA ladder (lambda).

Figure S5 - Position of $\mathrm{CCE04}{ }^{\mathrm{SR}-\mathrm{VP}}$ and $\mathrm{CCE04}^{\text {London }}$ within $\mathrm{T}$. urticae CCE phylogeny.

Maximum likelihood phylogeny of T. urticae, D. melanogaster and A. mellifera CCEs, a selection of $L$. polyphemus CCEs and acetyl-choline esterases (AChEs) from D. pulex and B. mori. CCEs clustered into classes and/or clades ${ }^{43}$ : A-C (dietary class), D-G (hormone/semiochemical class), H (glutactin and like enzymes), I (uncharacterized conserved insect CCEs), $\mathrm{J}$ (AChEs), $\mathrm{K}$ (gliotactins), $\mathrm{L}$ (neuroligins) and $\mathrm{M}$ (neurotactins). T. urticae specific CCE expansions ${ }^{37}$ are indicated with J" (22 members) and J' (32 members), while uncharacterized conserved chelicerate CCEs are indicated with the letter U (this study). In Grbic et al. 2011, TuCCE15 and TuCCE16 weakly clustered with insect glutactins, but as this could not be confirmed by the analysis in this study and both CCEs clustered with high bootstrap support with a L. polyphemus CCE, TuCCE15 and TuCCE16 were assigned to a U clade. TuCCE25 and TuCCE21 were grouped into clade F' as these two T. urticae CCEs showed, compared to other $T$. urticae CCEs, the highest similarity (based on BLASTp E-value, data not shown) to insect juvenile hormone esterases (clade $\mathrm{F}$ insect $\mathrm{CCEs}^{43}$ ) in the ESTHER database. ${ }^{63}$ Only bootstrap values above $65 \%$ are shown. The scale bar represents 0.5 amino-acid substitutions per site. The CCE protein sequences used for phylogenetic analysis can be found in File S2. Both CCE04 ${ }^{\mathrm{SR}-\mathrm{VP}}$ and $\mathrm{CCE} 04^{\mathrm{London}}$ clustered within clade $\mathrm{J}$ " and are indicated by a red and black arrow, respectively.

Figure S6 - SDS-PAGE and Western blotting of both purified CCE04 isoforms. Left, stain free SDS page; right: Western blot. Mw: molecular weight protein ladder (Precision Plus Protein Standard)

Table S1 - Primers used in this study.

Table S2 - Catalytic triad residues, signal peptide prediction and GxSxG motif in $T$. urticae CCEs belonging to clade $\mathrm{J}$ ' and $\mathrm{J}$ '” 
File S1- Coding sequence of $\mathrm{CCEO4} 4^{\mathrm{Lndon}}$ and $\mathrm{CCEO} 4^{\mathrm{SR}-V P}$

File S2 - Arthropod CCE protein sequences used for maximum likelihood phylogeny. 
(a)

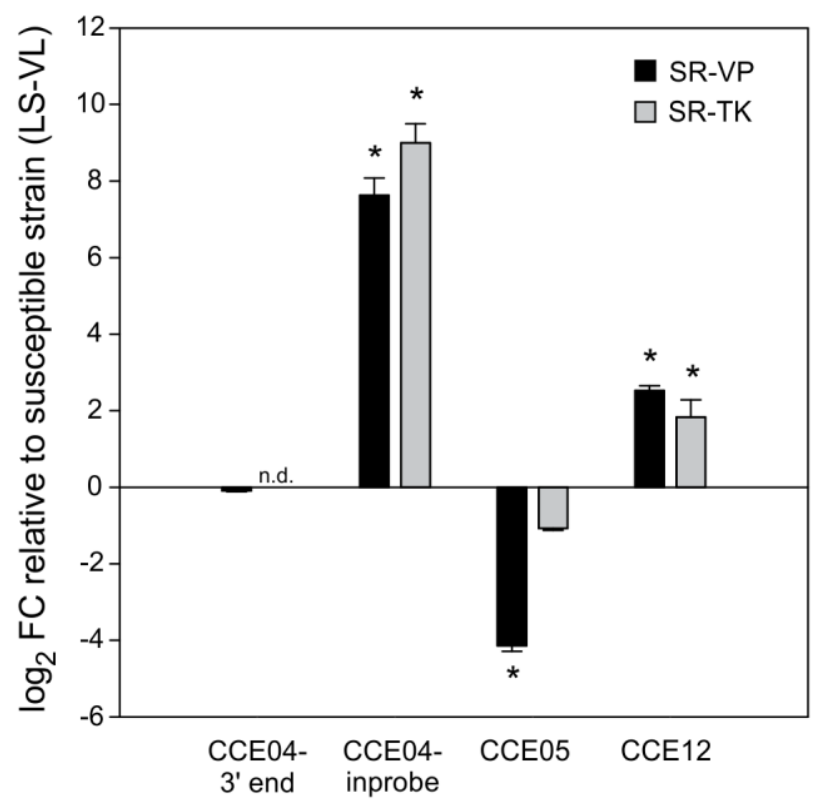

(b)

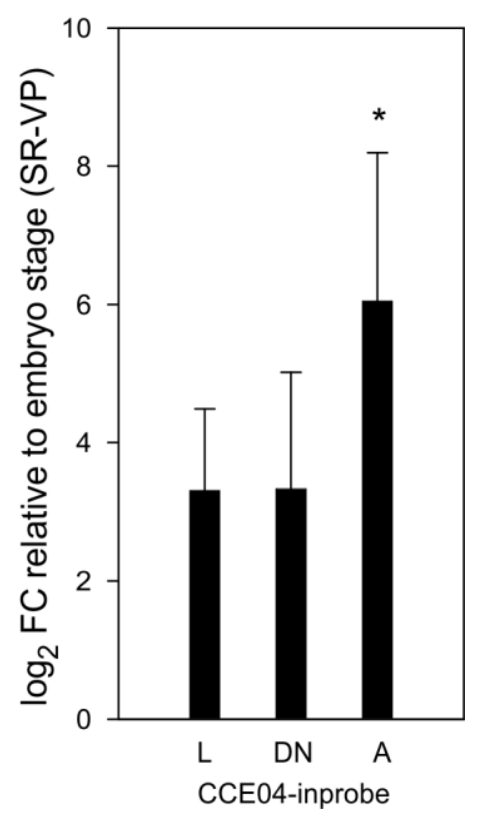

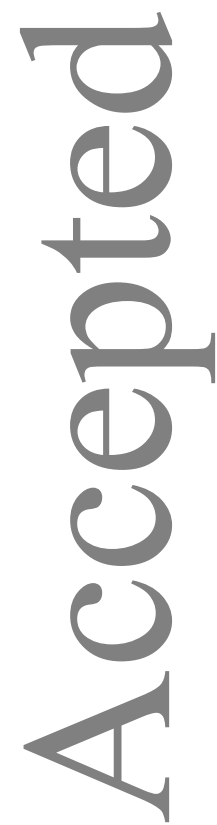

This article is protected by copyright. All rights reserved. 

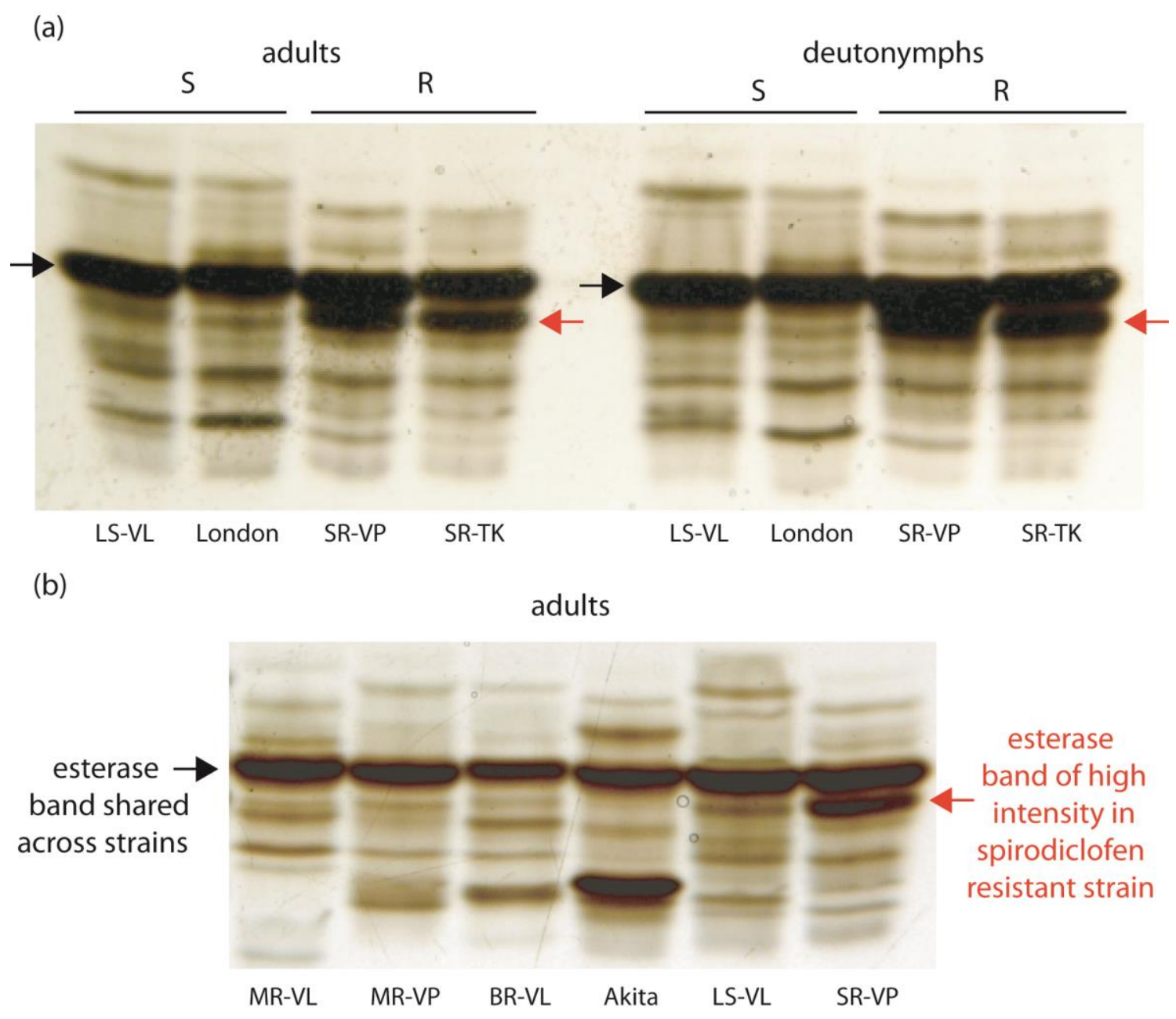

This article is protected by copyright. All rights reserved. 

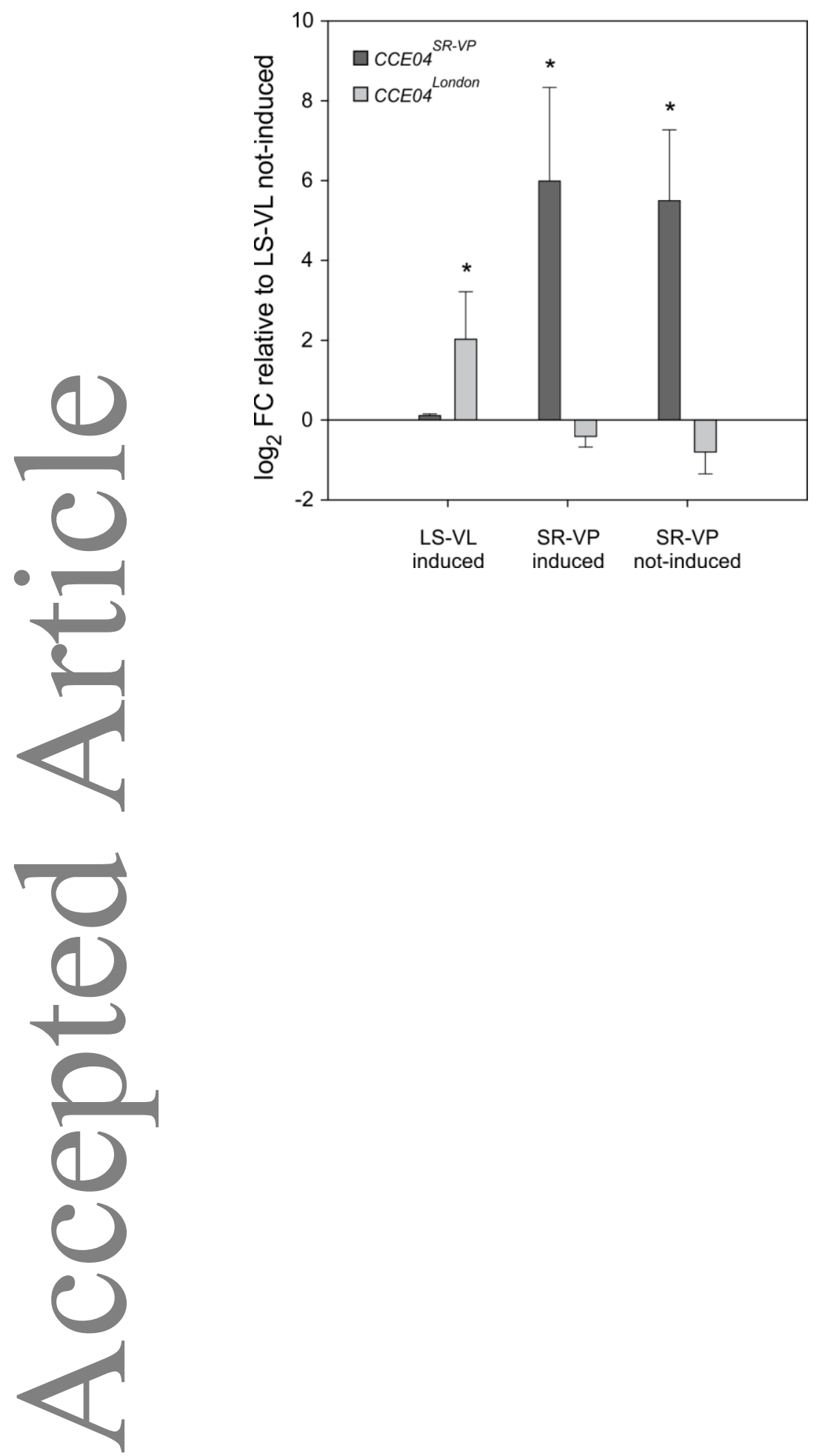

This article is protected by copyright. All rights reserved. 


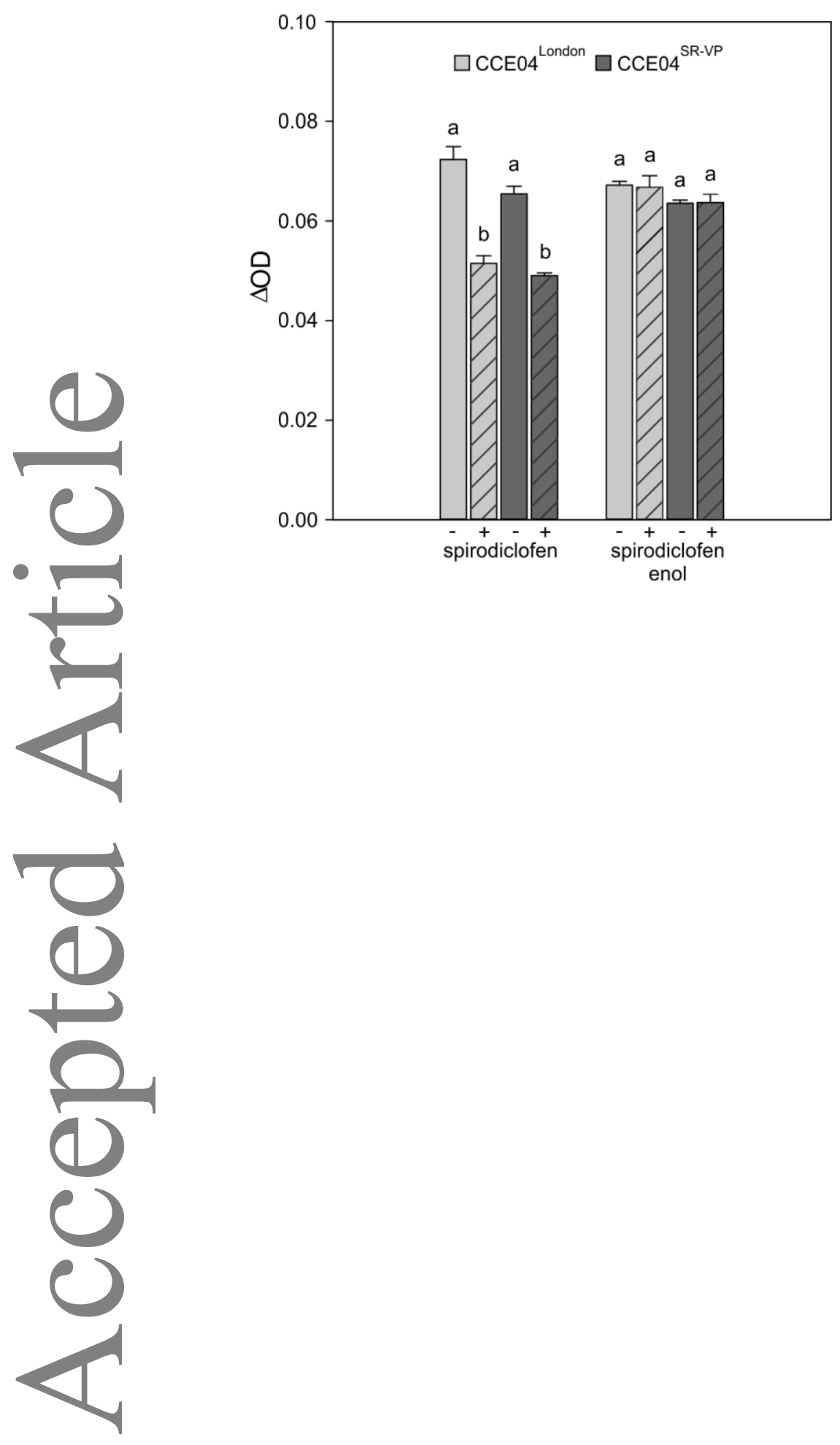

This article is protected by copyright. All rights reserved. 
(a)

spirodiclofen

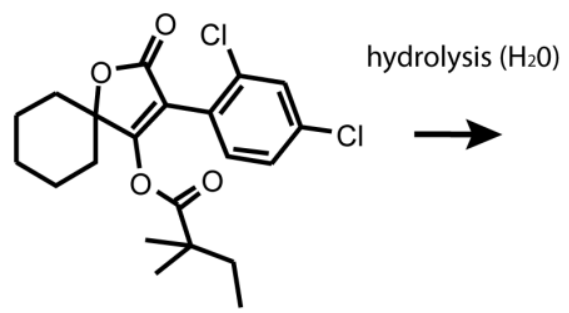

(b)

spirodiclofen

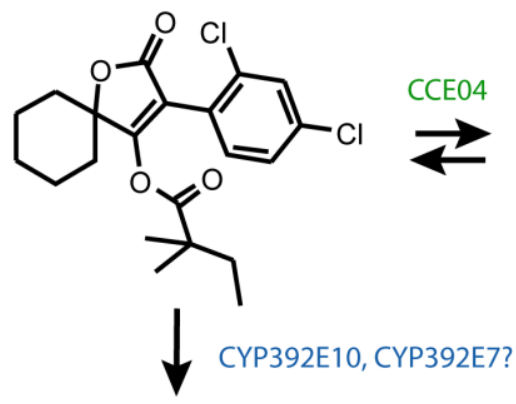

hydroxy spirodiclofen

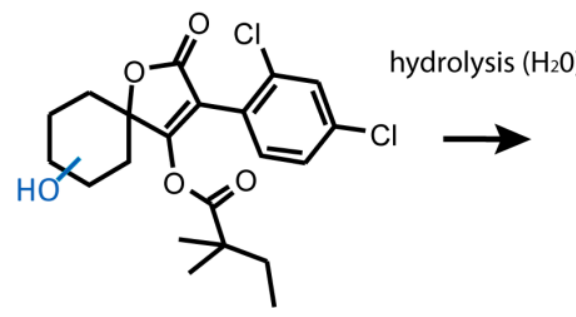

spirodiclofen enol (active)

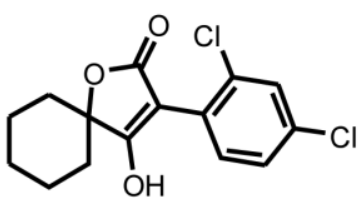

spirodiclofen sequestered by CCEO4
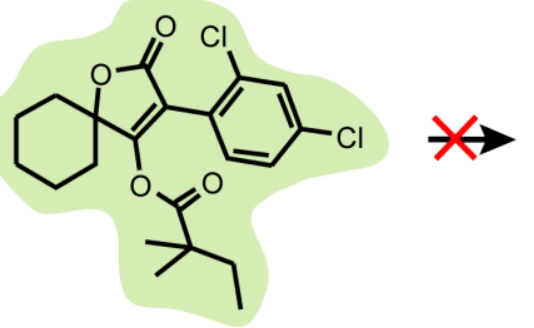

hydroxy spirodiclofen enol (not toxic)

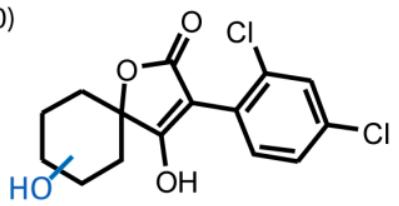

spirodiclofen enol (active)

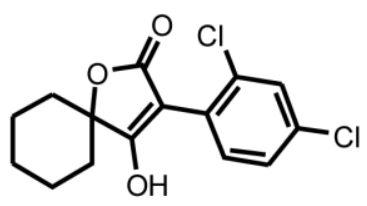

0

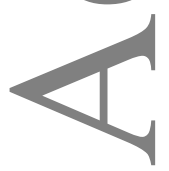

This article is protected by copyright. All rights reserved. 


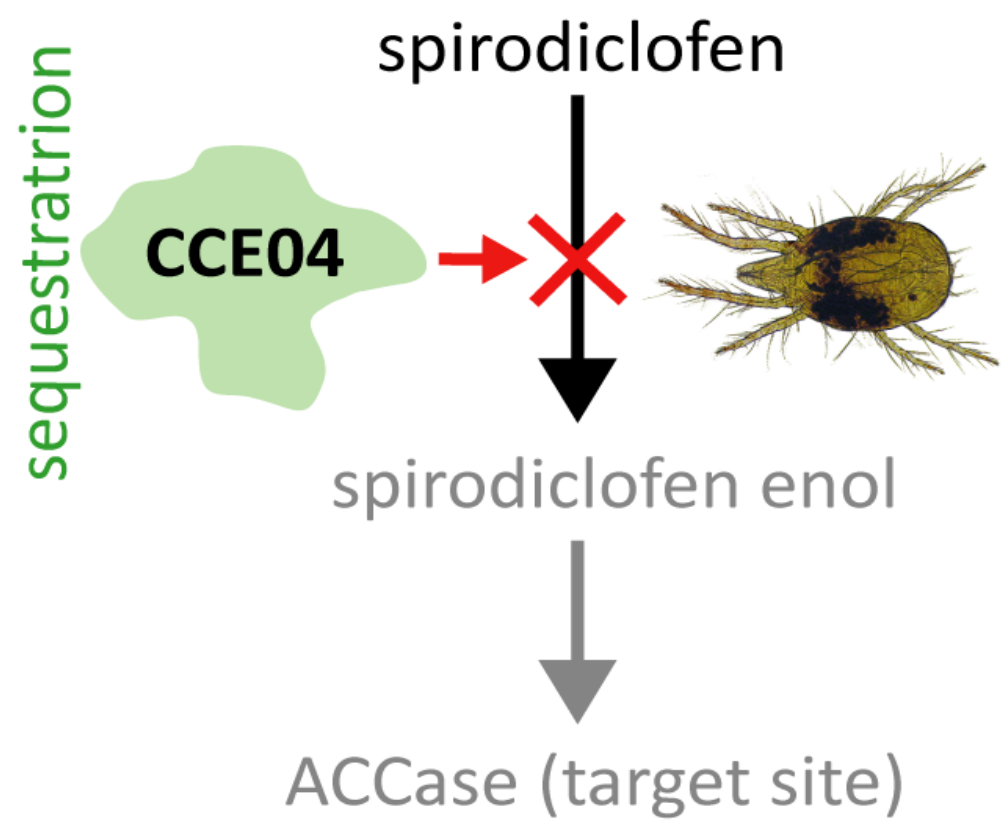

Selection with spirodiclofen resulted in enrichment of a specific carboxyl/choline esterase allele in two genetically independent spider mite strains. The role of this esterase in resistance to spirodiclofen is discussed. 